\title{
L'HOMME L'Homme
}

229 | 2019

Varia

\section{Salvatore D'Onofrio, Le Matin des dieux. Du Norouz persan aux Pâques chrétiennes}

Jean-Jacques Glassner

\section{(2) OpenEdition}

Édition électronique

URL : https://journals.openedition.org/lhomme/33755

DOI : 10.4000//homme.33755

ISSN : 1953-8103

Éditeur

Éditions de l'EHESS

\section{Édition imprimée}

Date de publication : 1 mars 2019

Pagination : 201-203

ISSN : 0439-4216

\section{Référence électronique}


S alvatore D'Onofrio se propose d'étudier à travers le monde la présence de pousses rituelles qui sont issues de la germination de graines de céréales, de légumineuses ou d'autres semences, à des époques et dans des lieux variables, telles qu'elles figurent dans le sabzeh iranien. Le comparatisme est à la source de ce travail.

Ces pousses sont cultivées par des femmes, pendant quelques semaines, à la lumière ou dans l'obscurité, dans des lieux qui se distribuent de l'Inde à l'Europe, voire jusqu'à l'Amérique du Nord, avant d'être jetées. Elles sont au cœur d'appareils symboliques qui marquent le passage du temps, le plus souvent au printemps, le Nouvel An comme en Iran (Noruz) ou Pâques comme en Italie du Sud. Mais leur présence peut se produire à d'autres moments du calendrier, comme pendant la canicule. Car il faut une impulsion rituelle qui permette de ne pas mourir avec le temps qui s'écoule, de franchir un seuil dans le registre de la temporalité.

L'enquête ethnographique s'organise principalement à Paris et sa banlieue, où se trouvent les représentants de nombre de communautés étrangères, et en Italie du Sud. L'auteur fait une présentation des différentes variables sous lesquelles se présente le rituel. Outre l'Iran et l'Inde avec les zoroastriens, sont pris en compte, successivement, les Kazakhs de Mongolie ou les Ouïgours de Chine, l'Ouzbékistan, le Tadjikistan, l'Afghanistan, la Géorgie, l'Arménie, l'Azerbaïdjan, les Maronites du Liban, les Yézidis, les Kurdes, les États-Unis, la Pologne, la Provence, les juifs de Rome et de Vénétie, la Calabre, la Sicile et la Sardaigne.

En Iran, le sabzeh est placé sur une table qui doit présenter sept éléments différents. Pour expliquer ce nombre, l'auteur renvoie à la littérature mésopotamienne où le 7 signale une période de temps qui est achevée et après laquelle une nouvelle prend naissance.
Soit dit en passant, l'assertion voulant que le combat qui oppose Gilgamesh à Enkidu s'achèverait sans vainqueur n'est plus admise. Chez les zoroastriens et les Yézidis, le même chiffre apparaît au moment de la création, il correspond au nombre d'anges auxquels le dieu tout-puissant a donné vie, et au nombre de jours que dure la célébration de la fête du Nouvel An. On regrette que l'auteur n'analyse pas de façon plus approfondie le symbolisme du sept dans les cultures iranienne et indienne.

Les pousses sont associées aux idées de mort et de résurrection. Le Nouvel An, précisément, correspond à l'éveil de la nature, au passage de la mort à la vie au moyen de la répétition de la cosmogonie et à la purification des péchés. En terres chrétiennes, leur présence rappelle que l'année n'a pas toujours et partout commencé le $1^{\text {er }}$ janvier, mais au printemps, avec le renouveau des cultures. En Mésopotamie ou en Syrie antiques, comme à Palmyre, elle pouvait commencer à l'équinoxe d'automne. À l'origine, la fête était célébrée deux fois l'an, au printemps et à l'automne, au moment des deux équinoxes. Plus tard, elle le fut soit à l'une, soit à l'autre. Mais on ne trouve pas trace, alors, de cultures des pousses.

La date du $1^{\text {er }}$ janvier pour le début de l'année fut instituée par Jules César. Elle fut abandonnée avec la montée du christianisme. Le $1^{\text {er }}$ mars fut retenu sous les rois mérovingiens, le 25 décembre sous les Carolingiens, le jour de Pâques ailleurs. Il fallut attendre l'édit de Charles IX, le 9 août 1564 , pour voir le $1^{\text {er }}$ janvier généralisé dans le royaume de France, et l'an 1582 pour que le pape Grégoire XIII l'impose à toute la chrétienté catholique. Le maintien de la tradition de la culture des pousses exigea donc des accommodements calendaires.

L'origine du rituel n'est pas en Perse zoroastrienne. Ni l'Avesta, ni les milieux 
parsis de la diaspora indienne, ni la littérature ne connaissent les tables sur lesquelles les pousses sont présentées. L'auteur suggère du bout des lèvres que la tradition fut peutêtre empruntée aux pays conquis par la Perse à l'époque achéménide, ou qu'elle apparut plus tard, au contact de l'Islam. La légende veut que l'usage d'une nappe ait été introduit par le roi Jamshid, le quatrième monarque à avoir régné sur terre selon le Shâhnâmeh (Le Livre des rois). L'idée, selon laquelle le fait d'accomplir le rite permettrait de s'identifier à un dieu ou de le représenter, pourrait être un emprunt au mithraïsme.

La continuité territoriale, dans la célébration du rite, de l'Iran et de la Chine à l'Europe, semble accréditer l'hypothèse d'une propagation centrifuge, une hypothèse contredite par l'exemple hopi de Californie, qui conduit à le penser en termes d'universaux culturels. Partant, l'auteur attribue au rite une valeur analogue au mythe de référence du dénicheur d'oiseaux des Bororo. En réalité, de bout en bout de son ouvrage, il choisit d'adopter une "voie intermédiaire», un "structuralisme mitigé", "réunissant l'étude d'un fait culturel en un seul lieu et celle du même fait recouvrant plusieurs sociétés dont la contiguïté dans l'espace réclame l'utilisation d'appareils analytiques plus sophistiqués» (pp. 237-238).

Les principaux traits caractéristiques des rituels sont:

- les dates: le rituel est prioritairement accompli à l'équinoxe du printemps. Selon les sociétés, la date peut varier, la signification des pousses changeant dans leur rapport au calendrier. En Grèce antique, dans les jardins d'Adonis, l'ensemencement se déroulait au cour de l'été, la période du vide végétal après la moisson. Dans les communautés juives, en France et à Rome, les pousses sont mises à germer entre Roch Hachana et Yom Kippour. Chez les Hopi, les pousses sont plantées en février ou juillet. En terres chrétiennes, plusieurs dates sont avancées, selon les provinces, autour des équinoxes de printemps ou d'automne, des solstices d'hiver et d'été;
- les ingrédients et les objets: les tables rituelles présentent sept choses (haft sin en iranien) dont les noms commencent théoriquement par la lettre « $s$ » (mais il n'est à cela nulle obligation; la lettre «sh" peut aussi faire l'affaire), habituellement le sabzeh, des pousses de blé, d'orge ou de lentilles, auxquelles s'ajoutent le samanu (une pâte sucrée faite entièrement de graines germées), l'ail (sir), la pomme (sib), le somaq, les fruits secs du jujubier (senjed) et le vinaigre (serkeh). Il existe même un Noruz sans le sabzeh. Les variantes résultent d'ajustements, qui n'affectent pas la signification générale du rituel;

- les célébrations: elles sont variables. Des moments importants sont associés à la manipulation du feu ou de la lumière. Au cours des jours qui précèdent Noruz, les Iraniens sautent par-dessus des feux allumés, leur transmettant leurs faiblesses et y puisant leur santé. Le jour de Noruz, la lumière chassant l'obscurité, les feux devenus inutiles sont éteints et les cendres enterrées. Un moment fort du livre réside dans le rapprochement esquissé par l'auteur entre la tradition des pousses et un rite observé par Louis Dumont chez les Pramalai Kallar, en Inde du Sud. Alors que ce rite était considéré par Dumont comme unique, l'auteur est en mesure de le rapprocher de données recueillies à Madurai, toujours en Inde du Sud, à Bari Sardo et à Samugheo en Sardaigne. À l'arrière-plan des rites associés au solstice d'été, l'auteur identifie avec raison le mythe d'Adonis et ses jardins stériles, qui symbolisent l'inversion des valeurs de l'agriculture, non pas une négation absolue, mais une «contrepartie» (Jean-Pierre Vernant) de la culture. En milieu zoroastrien, également, un rapport ambivalent unit le Nouvel An à la mort. À ce propos, l'auteur évoque la figure de Haji Firuz, un gardien du feu dans le zoroastrisme, qui annonce le printemps, mais stigmatise aussi les rigidités du passé. Associé au retour des morts, il est parfois rapproché du Dumuzi sumérien ou du Tammuz babylonien, considérés comme les prototypes du dieu mourant et renaissant. En Mésopotamie, la figure du dieu 
qui meurt et ressuscite semble, davantage qu'Adonis, liée aux rythmes des saisons. Il affronte Enkimdu, le dieu des agriculteurs, et se voit accorder six mois de présence sur terre, les six autres aux Enfers. Son retour sur terre se situe le 25 de Du'uzu (début juillet); son absence s'étend, au moins, de janvier à avril. Mais ces faits sont loin d'être assurés et d'aucuns voient en lui l'incarnation de la sève des arbres, des grains des céréales et du lait du bétail. Décidément, la Mésopotamie ne peut être associée aux rites des pousses. En Égypte, la tradition est, en revanche, bien attestée (pp. 153-154).

- les acteurs: ce sont les femmes qui font germer les pousses, aidées dans certains cas par les enfants, alors même que celles-ci appartiennent aux espèces horticoles normalement cultivées par les hommes. Ces derniers ne sont pas totalement absents; la coexistence du feu (avatar du sang) et du sabzeh permet d'organiser le travail fondé sur la division des sexes, le premier étant affaire d'hommes, le second de femmes. En Calabre, dans la ville de Nocera Terinese, des flagellants font saigner leur corps, accompagnés par de jeunes garçons, généralement leurs fils; les garçons représentent de manière métaphorique l'absence de fécondité, les adultes étant porteurs d'une fécondité particulière, de type masculine, mais recouvrant certaines fonctions féminines, celles qui sont absentes du corps de la Vierge (pp. 218-219). Les morts tiennent toute leur place dans ce rituel. Le processus raccourci de germination des graines, l'allumage des feux et le nettoyage des maisons servent à les accueillir, mais, plus encore, à accélérer leur départ. En Sicile, les pousses sont associées à la mort du Christ, comme en témoignent les noms sepulcri ou sibburca qu'on leur donne. En Calabre, à Fuscaldo et ses environs, elles sont appelées grani, et sont soit déposées dans les églises (Fuscaldo), soit sur les monuments aux morts (Scarcelli) $)^{1}$. En Iran aussi il est courant de déposer le sabzeh sur les tombes de ses propres morts (p. 93).

- la fin du rituel : en jetant les pousses, on se défait de tous les maux de l'année écoulée. Le geste souligne l'ambivalence entre le mal que l'on veut chasser et le bien que l'on souhaite attirer.

Symbolisant le réveil de la nature après l'hiver, les pousses célèbrent le retour de la végétation et la fécondité du cosmos. Les paroles, les objets et les gestes associés au rite renvoient à la mythologie qui les accompagne. Selon les conceptions zoroastriennes, chacune des sept choses présentes sur la table est mise en adéquation avec une puissance supérieure. En Sicile, les pousses se nomment lavureddi, un diminutif de lavuri, "champ de blé en herbe", du mot labor/lavurari, "labourer». Le mot fait clairement allusion à la chaîne agricole. À l'opposé, les pousses ont des équivalents qui en inversent la signification qui leur est attachée et peuvent exprimer un rapport de congruence avec une semence stérile, celle d'Adonis, un dieu sans progéniture, voué à une fin précoce.

Il est difficile de rendre compte de toute la richesse de l'ouvrage. L'auteur échappe à l'indigence des interprétations qui tentent d'épuiser la signification des mythes en les ramenant à un seul code. Il montre que plusieurs niveaux de lecture superposés s'imposent pour une bonne intelligence des rites, des codes végétal, agraire, alimentaire, social et temporel. Il relève avec soin le réseau des oppositions qui encadrent dans chaque société les faits étudiés, avec les mécanismes d'inversion qui les caractérisent. Malgré la virtuosité qu'il déploie dans l'analyse, on se demande parfois si les écarts très considérables entre les mythes auxquels il tente de donner une même armature ne forcent pas l'emploi qu'il fait des règles de transformation. On pense à l'évocation d'Osiris en Égypte ancienne, à la fête de Halloween aux États-Unis. On le soupçonne, dans ces cas, d'avoir recours à un comparatisme procédant par assimilation directe, sans tenir compte des spécificités de chaque culture. Mais cela est un débat qui reste toujours ouvert.

\section{Jean-Jacques Glassner}

1. Je dois ces informations à Augusta Leta, que je tiens à remercier. 